\title{
Anemia in Adult Celiac Disease; Presentation with Iron Deficiency Anemia Masked by Colon Cancer
}

\author{
Hugh James Freeman* \\ Department of Medicine (Gastroenterology), University of British Columbia, Vancouver, BC, Canada \\ *Corresponding author: hugfree@shaw.ca \\ Received December 02, 2014; Revised December 10, 2014; Accepted December 28, 2014
}

\begin{abstract}
An elderly physician with iron deficiency anemia and early stage colon cancer localized in the cecum was treated successfully with laparoscopic right hemicolectomy. Despite treatment, her iron deficiency anemia persisted. Subsequent investigations revealed occult celiac disease that completely resolved with a gluten-free diet alone. Iron deficiency anemia in celiac disease may have multiple causes including reduced duodenal iron absorption because of reduced absorptive surface area, alterations or mutations in iron regulatory proteins critical for normal iron absorption, superimposed occult blood loss from different causes including benign and malignant small bowel ulceration, and low grade intravascular hemolysis. Although iron deficiency anemia may be the sole presenting clinical manifestation of occult celiac disease without other typical symptoms, such as diarrhea or weight loss, a very thorough gastrointestinal assessment is essential to exclude other causes of iron deficiency anemia. Conversely, persistent or refractory iron deficiency anemia may represent a clue to unrecognized celiac disease, even in the elderly.
\end{abstract}

Keywords: celiac disease, colon cancer, iron deficiency anemia, anemia in celiac disease

Cite This Article: Hugh James Freeman, "Anemia in Adult Celiac Disease; Presentation with Iron Deficiency Anemia Masked by Colon Cancer.” International Journal of Celiac Disease, vol. 3, no. 1 (2015): 3336. doi: 10.12691/ijcd-3-1-2.

\section{Introduction}

Isolated iron deficiency anemia in the absence of other symptoms may occur in the elderly with colonic cancer, especially if the cancer is located in the cecum. This probably results from low grade chronic or intermittent blood loss. A similar clinical phenomenon of isolated iron deficiency anemia in celiac disease may occur, even in the absence of diarrhea and weight loss. In large part, this may be due to impaired duodenal mucosal iron absorption from the proximal small intestinal lumen, the main small intestinal site involved in adult celiac disease $[1,2,3]$.

\section{Case Report}

In 2002, a 69-yr-old retired post-menopausal female physician presented to her colleague with mild right lower quadrant abdominal discomfort, intermittently present for more than a decade. There was no diarrhea, constipation, weight loss or rectal bleeding and fecal occult blood testing was negative. Flexible sigmoidoscopy was normal and barium enema revealed diverticulosis, while ultrasound and computerized tomography of her abdomen and pelvis were normal. She had hypothyroidism, treated with replacement thyroid. Family history revealed her mother died with a colon cancer at age 75 years. As a result, she was referred for screening colonoscopy and this examination was normal.
In 2007, she returned for colonoscopic review. Her symptoms had resolved without treatment. Fecal occult blood testing during the intervening years was negative. However, her hemoglobin was now 119 g/L (normal, 120155 ) and iron studies suggested mild iron deficiency with serum iron 8 umol/L (normal, 9-30), iron binding capacity $77 \mathrm{umol} / \mathrm{L}$ (normal, 45-73) and serum ferritin $14 \mathrm{ug} / \mathrm{L}$ (normal, 20-300). Other blood studies, including liver chemistry tests, red cell folate, and serum vitamin B12, were normal but serum albumin was 32 g/L (normal, 3450). Colonoscopy showed sigmoid diverticulosis and a flat tubular adenoma, estimated to be less than $5 \mathrm{~mm}$, in the distal ascending colon that was removed with cold snare. In addition, a suspicious-appearing flat mucosal fold was detected in the cecum. Biopsies of this fold showed severely dysplastic epithelium and subsequent laparoscopic right hemicolectomy confirmed a localized well-differentiated colon adenocarcinoma with 14 negative lymph nodes.

In 2009, she reported vague abdominal bloating discomfort. Blood tests were normal except for mild anemia (hgb, $118 \mathrm{~g} / \mathrm{L}$ ) and persistent iron deficiency with a low serum ferritin, $12 \mathrm{ug} / \mathrm{L}$. IgA tissue transglutaminase antibodies were markedly increased (145 EU; normal, up to 20) and upper endoscopy revealed macroscopic duodenal changes with scalloping. Biopsies showed moderate to severe architectural mucosal changes with flattened villi and hyperplastic crypt epithelium as well as intra-epithelial lymphocytosis, typical of untreated celiac disease [4]. Colonoscopy confirmed a well-healed ileocolonic 
surgical anastomosis but no new neoplastic changes. She was treated with a gluten-free diet alone.

In late 2010, she was re-evaluated. Her hemoglobin was $150 \mathrm{~g} / \mathrm{L}$, serum albumin was $36 \mathrm{~g} / \mathrm{L}$, all iron studies were normal and tissue transglutaminase was normal at 9 EU. In 2011, colonoscopy and endoscopic duodenal biopsies were normal. Interestingly, over the year, a male maternal cousin and his daughter were diagnosed with celiac disease.

\section{Discussion}

This physician presented with iron deficiency anemia and an early stage colon cancer. Despite resection of this localized cancer, her iron deficiency persisted and further serological and biopsy studies revealed celiac disease. After treatment with a gluten-free diet, her iron deficiency resolved and severely abnormal serological results and duodenal biopsy changes normalized. In retrospect, this presentation in an elderly postmenopausal female with iron deficiency anemia probably resulted from chronic and intermittent low grade blood loss from her colonic cancer, but coupled with impaired duodenal absorption of dietary iron. In the past decade, the critical processes involved in duodenal mucosal uptake of dietary iron and the systematic regulation and control of these enterocyte iron uptake processes have become increasingly appreciated and their alterations, particularly in celiac disease, are worthy of further exploration.

\subsection{Iron Absorption in the Duodenum}

Normally, uptake of iron occurs in ferrous form by a brush border membrane transport protein, the divalent metal transporter (DMT1), found in duodenal enterocytes. DMT1 is a microvillus transmembrane protein that may also transport other divalent metals [5] and DMT1 functions as a co-transporter with protons [6]. Human mutations of DMT1 causing microcytic anemia have also been identified [7]. It is not known, however, if these mutations occur sporadically or may be statistically linked to specific disorders, like celiac disease. Iron transport by DMT1 also requires initial conversion of ferric iron, the predominant dietary form, to ferrous iron due to ferric reductase activities. These reductase enzyme activities are integral to the apical surface of the intestinal enterocyte and require an acidic membrane microenvironment. Within the enterocyte, ferritin appears to be able to store large amounts of iron permitting controlled delivery of iron to the basolateral membrane.

Iron exits the duodenal enterocyte through the action of a separate protein, ferroportin, highly expressed in the basolateral membrane. Iron then enters the blood binding to a separate transport protein, transferrin, so that the iron can be delivered to developing red cells. Transferrin is a glycosylated protein capable of carrying two ferric ions to target tissues. Before binding to transferrin, the ferrous ions require conversion to ferric ions by oxygendependent ferroxidases (eg., hephaestin, ceruloplasmin) [8]. A deficiency of these ferroxidases impedes absorption of iron. Excess iron in the blood can also be stored in the liver, available for transport to developing red blood cells.

\subsection{Regulation of Iron Uptake}

Iron levels are usually well maintained. During periods of iron deficiency, iron absorption may be increased, but decreased with iron overload [9]. A major regulator of iron homeostasis is believed to be hepcidin, basically a hormonal regulator, discovered only in the past decade or so [10]. Hepcidin is synthesized and secreted by hepatocytes. The concentration of hepcidin is affected by plasma and tissue iron stores. Hepcidin circulates in plasma, mostly in free form, and may be filtered by the kidneys. Hepcidin regulates iron flow into plasma by binding and inhibiting ferroportin. Impaired iron absorption occurs and release of iron into the circulation from both the enterocyte and hepatocyte stores is reduced. Human ferroportin mutations have been reported $[11,12]$ that appear to prevent hepcidin binding and create iron overload states. Hepcidin may itself be regulated by a bone marrow suppressor of hepcidin that responds to increased erythropoietin from hypoxia or hemorrhage $[13,14]$. Other homeostatic mechanisms not appearing to be reliant on hepcidin include hypoxia and cellular iron deficiency. Both of these may independently increase ferroportin $[15,16]$.

\subsection{Iron Deficiency in Celiac Disease}

There may be a number of factors that lead to iron deficiency anemia in celiac disease. These include reduced duodenal iron absorption, gastrointestinal blood loss, and others, including low grade intravascular hemolysis with increased urinary loss of iron detected using colorimetric methods as urine hemosiderin.

\subsection{Reduced Duodenal Iron Absorption}

Clinical and other features of celiac disease have been reviewed elsewhere $[17,18]$. Iron deficiency anemia may occur with well established celiac disease, or may lead to its initial recognition, especially if a colonic cause has been excluded and the anemia is refractory to oral iron treatment [19]. In the present case, an early node-negative colon cancer, located in the cecum, was detected. Although fecal occult blood testing was always negative, blood loss from a localized early colon cancer could still have been responsible. Later, persistent iron deficiency was noted, in retrospect, thought to be due to celiac disease. In celiac disease, impaired iron uptake reflects reduced surface absorptive area in the proximal small intestinal mucosal distribution of celiac disease and the usual site of iron enterocyte uptake in the duodenum. As a result of mucosal disease localized in the proximal duodenum in celiac disease, reduced duodenal iron absorption might be expected, even if added oral iron is provided. Recent diagnostic emphasis in celiac disease has been placed on micronutrient deficiency, particularly for iron, and iron deficiency anemia [20]. In children, iron deficiency anemia is frequently reported and screening with tissue transglutaminase antibodies has been recommended [21]. Pica may be the presenting symptom of celiac disease with iron deficiency anemia in children [22]. In adults, including the elderly, isolated iron deficiency anemia, as in the present case, may also be due to occult celiac disease.

\subsection{Gastrointestinal Blood Loss}

Although impaired iron absorption from the duodenum is usually considered the cause, reports have appeared of 
celiac disease in both adults and children having occult gastrointestinal bleeding [23,24,25,26]. In young males presenting with iron deficiency anemia, peptic ulcer disease was the most common finding occurring in 30\%, while the most common lower gastrointestinal tract causes, detected in 34\%, included hemorrhoids and inflammatory bowel disease [27]. In this series, malignant causes were not seen, as in the present case, and celiac disease was eventually diagnosed in $4 \%$. In some with celiac disease, other more common causes of blood loss should be considered. Most would recommend a thorough evaluation to identify the cause of iron deficiency anemia, including endoscopic and radiologic imaging studies [28]. Routine duodenal biopsy during upper endoscopic evaluation for iron deficiency [29] or other upper gastrointestinal symptoms [30] may uncover changes of untreated celiac disease. Recent studies have suggested that celiac disease with iron deficiency anemia is more likely to occur in Caucasians, than non-Caucasians [31]. In addition, celiac disease patients initially presenting with anemia tend to have more severe disease than celiac disease patients presenting with diarrhea [32]. Of course, celiac disease may be occasionally complicated by an associated or superimposed disorder, including small intestinal ulceration or lymphoma. Either benign or malignant neoplastic mucosal ulcers in celiac disease may cause occult or overt blood loss, positive fecal occult blood tests, and if chronically present over time, iron deficiency and anemia.

\subsection{Iron Deficiency and Hemolysis}

Intravascular hemolysis, possibly related to an autoimmune pathogenesis [33,34,35,36], with increased urinary iron losses should be considered. Colorimetric studies to determine the presence of urinary hemosiderin may be considered along with review of the peripheral blood smear. Evidence of hemolysis with these initial screening studies may result in a more detailed hematologic evaluation.

\subsection{Other Microcytic Anemias in Celiac Disease}

Occasionally, other causes of microcytic anemia may occur in celiac disease, including anemias associated with chronic inflammatory diseases, as well as a rare sideroblastic anemia associated with pyridoxine deficiency [37]. In this early report, the anemia responded completely to a gluten-free diet. In children, a rare disorder of iron deficiency anemia with idiopathic pulmonary hemosiderosis and celiac disease has been described, the so-called Lane-Hamilton syndrome [38]. In this report, improvement with a gluten-free diet was noted. In a larger series of 25 pediatric cases with idiopathic pulmonary hemosiderosis and hemoptysis reported from France, 28\% had celiac disease antibodies. In these 25 children, most required corticosteroids and immunosuppressants for their lung disorder [39].

\subsection{Regulation of Iron Absorption in Celiac Disease}

Studies on intestinal iron absorption in celiac disease have been limited. Early studies [40] confirmed that absorption of ferrous iron was reduced in untreated celiac disease, particularly if already iron deficient, and this absorption could be improved with a gluten free diet. This was attributed to reduced small intestinal absorptive surface area, particularly in the proximal small intestine.

Iron regulatory proteins have also been examined using duodenal biopsies [41,42]. DMT1, ferroportin, hephaestin and transferrin receptor protein mRNA levels were all increased in celiac disease with reduced body iron stores compared to controls, similar to anemic patients. Increased expression of these proteins in all iron-deficient patients suggested that iron absorption capacity is upregulated in celiac disease as a consequence of iron deficiency, and not directly related to an increase in enterocyte proliferation [41]. In contrast, another study showed that expression of DMT1 and ferroportin were increased in celiac disease with or without iron deficiency [42].

\section{Conclusion}

Iron is a key micronutrient that may be depleted in children and adults with celiac disease, even in the elderly. Iron deficiency anemia may complicate established celiac disease, or represent a specific presenting extra-intestinal clinical feature. Iron deficiency anemia deserves to be thoroughly evaluated to exclude other common causes, including colon cancer, and if celiac disease is already known to exist, other superimposed causes of iron deficiency should be excluded, particularly if the anemia is refractory to oral iron replacement. Celiac disease may be complicated by colon cancer, but some studies have suggested that this is not as common as for other malignant intestinal disorders, including lymphoma [43]. This report emphasizes that persistent iron deficiency anemia should be thoroughly evaluated, even if a sinister malignant cause, such as colon cancer, is the initial presenting clinical feature. In the elderly, this may be particularly important since celiac disease is now becoming increasingly recognized [44], particularly with use of serological screening methods for case finding.

\section{References}

[1] Halfdanarson TR, Litzow MR, Murray JA. Hematologic manifestations of celiac disease. Blood 2007; 109: 412-421.

[2] Bottaro G, Cataldo F, Rotolo N, Spina M, Corazza GR. The clinical pattern of subclinical/silent celiac disease: an analysis of 1026 consecutive cases. Am J Gastroenterol 1999; 94; 691-696.

[3] Hoffbrand AV. Anemia in adult celiac disease. Clin Gastroenterol 1974; 3: 71-89.

[4] Freeman HJ. Small intestinal mucosal biopsy for investigation of diarrhea and malabsorption in adults. Clin Gastroenterol 2000; 10: 739-753.

[5] Illing AC, Shawki A, Cunningham CL, Mackenzie B. Substrate profile and metal-ion selectivity of human divalent metal-ion transporter-1. J Biol Chem 2012; 287: 30485-30496.

[6] Gunshin H, Mackenzie B, Berger UV, Gunshin Y, Romero MF, Boron WF, Nussberger S, Gollan JL, Hediger MA. Cloning and characterization of a mammalian proton-coupled metal-ion cotransporter. Nature 1997; 388: 482-488.

[7] Iolascon A, De FL. Mutations in the gene encoding DMT1: clinical presentation and treatment. Semin Hematol 2009; 46: 358370.

[8] Cherukuri S, Potla S, Sarkar J, Nurko S, Fox PL. Unexpected role of ceruloplasmin in intestinal iron absorption. Cell Metab 2005; 2: 309-319. 
[9] Finch C. Regulators of iron balance in humans. Blood 1994; 84: 1697-1702.

[10] Ganz T. Hepcidin and iron regulation. 10 years later. Blood 2011; 117: 4425-4433.

[11] Sham RL, Phatak PD, Nemeth E, Ganz T. Hereditary hemochromatosis due to resistance to hepcidin: high hepcidin concentrations in a family with C326S ferroportin mutation. Blood 2009; 114: 494-494.

[12] Sham RL, Phatak PD, West C, Lee P, Andrews C, Beutler E. Autosomal dominant hereditary hemochromatosis associated with a novel ferroportin mutation and unique clinical features. Blood Cells Molecules Diseases 2005; 34: 157-161.

[13] Liu Q, Davidoff O, Nas K, Hasse VH. Hypoxia-inducible factor regulates hepcidin via erythropoietin-induced erythropoesis. J Clin Invest 2012; 122: 4635-4644.

[14] Mastrogiannaki M, Matak P, Mathieu JR, Delga S, Mayeux P, Vaulont S, Peyssonnaux C. Hepatic hypoxia-inducible factor-2 down regulates hepcidin expression in mice through an erythropoietin-mediated increase in erythropoesis. Haematologica 2012; 97: 827-834.

[15] Ganz T. Systemic iron homeostasis. Physiol Rev 2013; 93: 17211741.

[16] Gulec S, Anderson GJ, Collins JF. Mechanistic and regulatory aspects of intestinal iron absorption. Am J Physiol Gastrointest Liver Physiol 2014; 307: G397-G409.

[17] Freeman HJ, Chopra A, Clandinin MT, Thomson AB. Recent advances in celiac disease. World J Gastroenterol 2011; 17: 22592272.

[18] Gujral N, Freeman HJ, Thomson AB. Celiac disease: prevalence, diagnosis, pathogenesis and treatment. World $\mathrm{J}$ Gastroenterol 2012; 18: 6036-6059.

[19] Annibale B, Capurso G, Chistolini A, D’Ambra G, DiGiulio E, Monarca B, DelleFave G. Gastrointestinal causes of refractory iron deficiency anemia in patients with gastrointestinal symptoms. Am J Med 2001; 111: 439-445.

[20] Oxentenko AS, Murray JA. Celiac disease: ten things that every gastroenterologist should know. Clin Gastroenterol Hepatol 2014; In press.

[21] Ertekin V, Tozun MS, Kucuk N. The prevalence of celiac disease in children with iron-deficiency anemia. Turk J Gastroenterol 2013; 24: 334-338.

[22] Korman SH. Pica as a presenting symptom in childhood celiac disease. Am J Clin Nutr 1990; 51: 139-141.

[23] Kosnai I, Kuitunen P, Siimes MA. Iron deficiency in children with celiac disease on treatment with a gluten-free diet. Role of intestinal blood loss. Arch Dis Child 1979; 54: 375-378.

[24] Fine KD. The prevalence of occult gastrointestinal bleeding in celiac sprue. $N$ Engl J Med 1996; 334: 1163-1167.

[25] Shamir R, Levine A, Yalon-Hacohen M, Shapiro R, Zahavi I, Rosenbach Y, Lemer A, Dinari G. Fecal occult blood in children with celiac disease. Eur J Pediatr 2000; 159: 832-834.

[26] Mant M, Bain VG, Maguire CG, Murland K, Yacyshyn BR. Prevalence of occult gastrointestinal bleeding in celiac disease. Clin Gastroenterol Hepatol 2006; 4: 451-454.

[27] Carter D, Levi G, Tzur D, Novis B, Avidan B. Prevalence and predictive factors for gastrointestinal pathology in young men evaluated for iron deficiency anemia. Dig Dis Sci 2013; 58: 12991305.
[28] Milano A, Balatsinou C, Fillippone A, Caldarella MP, Laterza F, Lapenna D, Pierdomenico SD, Pace F, Cuccunullo F, Neri M. A prospective evaluation of iron deficiency anemia in the GI endoscopy setting: role of standard endoscopy, videocapsule endoscopy, and C-enteroclysis. Gastrointest Endosc 2011; 73: 1002-1008.

[29] Emami MH, Karimi S, Kouhestani S. Is routine duodenal biopsy necessary for detection of celiac disease in patients presenting with iron deficiency anemia? Int J Prev Med 2012; 3: 273-277.

[30] Freeman HJ. Detection of adult celiac disease with duodenal screening biopsies over a 30-year period. Can J Gastroenterol 2013; 27: 405-408.

[31] Murray JA, McLachlan S, Adams PC, Eckfeldt JH, Garner CP, Vulpe CD, Gordeuk VR, Brantner T, Leiendecker-Foster C, Killeen AA, Acton RT, Barcellos LF, Nickerson DA, Beckman $\mathrm{KB}$, McLaren GD, McLaren CE. Association between celiac disease and iron deficiency in Caucasians, but not non-Caucasians. Clin Gastroenterol Hepatol 2013; 11: 808-814.

[32] Abu Dava H, Lebwohl B, Lewis SK, Green PH. Celiac disease patients presenting with anemia have more severe disease than those presenting with diarrhea. Clin Gastroenterol Hepatol 2013; 11: $1472-1477$.

[33] Miller DG. Celiac disease with autoimmune hemolytic anemia. Postgrad Med J 1984; 60: 629-630.

[34] Gabrielli M, Candelli M, Franceschi F, Cremonini F, Nista EC, Santarelli L, Villita A, Merra G, Girelli G, Gasbarrini G, Pola P, Gastbarrini A. Primary autoimmune hemolytic anemia and celiac disease. Scand J Gastroenterol 2004; 39: 605-606.

[35] Yarali N, Demirceken F, Kondolat M, Ozkasap S, Kara A, Tunc B. A rare condition associated with celiac disease: Evan's syndrome. J Pediatr Hematol Oncol 2007; 29: 633-635.

[36] Ivanovski P, Nikolic D, Dimitrijevic N, Ivanovski I, Perisic V. Erythrocytic transglutaminase inhibition hemolysis at presentation of celiac disease. World J Gastroenterol 2010; 16: 5647-5650.

[37] Dawson AM, Holdsworth CD, Pitcher CS. Sideroblastic anemia in adult celiac disease. Gut 1964; 5: 304-308.

[38] Hendrickx GF, Somers K, Vandenplas Y. Lane-Hamilton syndrome: case report and review of the literature. Eur J Pediatr 2011; 170: 1597-1602.

[39] Taytard J, Nathan N, de Blic J, Fayon M, Epaud R, Deschildre A, Troussier F, Lubrano M, Chiron R, Reix P, Cros P, Mahloul M, Michon D, Clement A, Corvol H; French RespiRare group. New insights into pediatric pulmonary hemosiderosis: the French RespiRare cohort. Orphanet J Rare Dis 2013; 8: 161.

[40] Anand BS, Callender St, Warner GT. Absorption of inorganic and hemoglobin iron in celiac disease. Br J Hematol 1977; 37: 409414.

[41] Barisani D, Parafioriti A, Bardella MT, Zoller H, Conte D, Armiraglio E, Trovato C, Koch RO, Weiss G. Adaptive changes of duodenal iron transport proteins in celiac disease. Physiol Genomics 2004; 17: 316-325.

[42] Sharma N, Begum J, Eksteen B, Elagib A, Brookes M, Cooper BT, Tselepis C, Iqbal TH. Differential ferritin expression is associated with iron deficiency in celiac disease. Eur $J$ Gastroenterol Hepatol 2009; 21: 794-804.

[43] Freeman HJ. Lymphoproliferative and intestinal malignancies in 214 patients with biopsy-defined celiac disease. J Clin Gastroenterol 2004; 38: 429-434.

[44] Freeman HJ. Clinical aspects of biopsy-defined celiac disease in the elderly. Can J Gastroenterol 1995; 9: 42-46. 